\title{
A high-fat diet increases body weight and circulating estradiol concentrations but does not improve bone structural properties in ovariectomized mice
}

\author{
Jay J. Cao ${ }^{1 *}$ and Brian R. Gregoire ${ }^{1}$ \\ ${ }^{1}$ USDA, Agricultural Research Service, Grand Forks Human Nutrition Research Center, \\ Grand Forks, ND 58202 \\ *Correspondence to: \\ Jay J. Cao, Ph.D. \\ USDA ARS Grand Forks Human Nutrition Research Center \\ $24202^{\text {nd }}$ Ave $\mathrm{N}$ \\ Grand Forks, ND 58202-9034 \\ Telephone: 701-795-8377, Fax: 701-795-8220 \\ Email: Jay.Cao@ars.usda.gov
}


${ }^{2}$ Abbreviations:

$\mu \mathrm{CT}$; micro computed tomography

CTSK; cathepsin K

Conn.D; connectivity density

CTR; calcitonin receptor

Itgb3; integrin $B 3$

OVX; ovariectomy

RANKL; receptor activator nuclear factor-KB ligand

Sham; sham-operated compared to OVX

SMI; structure model index

Tb.N; trabecular number

Tb.Sp; trabecular separation

Tb.Th; trabecular thickness

TRAP; tartrate-resistant acid phosphatase 


\section{Abstract}

Bone health is influenced by body mass and estrogen. The objective of the study was to determine whether high-fat diet induced obesity affects bone structure and alters markers of bone turnover in ovariectomized (OVX) mice. We hypothesized that a high-fat diet would increase body weight gain and serum estradiol levels in OVX mice but would not improve bone structural parameter in OVX mice. Thirty-five C57BL/6 mice were either sham-operated or OVX at age of 4 mo and then fed either a normal-fat diet (10\% $\mathrm{kcal}$ as fat) or a high-fat diet (45\% kcal as fat with extra fat from lard) ad libitum for $11 \mathrm{wks}$. Ovariectomy increased body weight, serum tartrate-resistant acid phosphatase concentration, and expression of cathepsin $\mathrm{K}$ in bone; decreased serum estradiol concentration; and induced significant bone loss manifested by decreased bone volume/total volume (BV/TV), Connectivity Density (Conn.D), trabecular number (Tb.N), and trabecular thickness (Tb.Th) with increased trabecular separation (Tb.Sp) and structural model index $(\mathrm{SMI})(\mathrm{P}<0.01)$. The high-fat diet increased body weight $(\mathrm{P}<$ $0.01)$ in ovariectomized mice and non-significantly decreased BV/TV $(\mathrm{P}=0.08)$ and Conn.D ( $\mathrm{P}=0.10)$. Despite having similar serum estradiol concentrations and higher body weight, ovariectomized mice consuming the high-fat diet had lower BV/TV,

Conn.D, Tb.N, Tb.Th and higher SMI and Tb.Sp than sham mice fed the normal-fat diet. These findings indicate that increased body weight and elevated serum estradiol concentration induced by a high-fat diet do not mitigate ovariectomy-induced bone loss in mice.

Keywords: Bone structure, obesity, high-fat diet, ovariectomy, mice 


\section{Introduction}

Despite being a risk factor for many chronic diseases, obesity, a global public health problem affecting more than 300 million people, has long been considered to be beneficial to bone health in humans [1]. The increased body weight and the ability of estrogen synthesis by adipose tissue are two primary reasons for the alleged beneficial effects of obesity on bone $[2,3]$.

In the U.S., about $9 \%$ of adults over the age of 50 have osteoporosis in either the femur neck or lumbar spine; an additional $49 \%$ have low bone mass and thus are at risk of developing the disease [4]. Women, accounting for $80 \%$ of individuals with osteoporosis, are especially at high risk mainly because of the sudden decrease in estrogen production associated with the loss of ovarian function at menopause [5].

Numerous studies have demonstrated that estrogen plays a critical role in bone metabolism. Estrogen deficiency following ovariectomy $(\mathrm{OVX})^{2}$ causes a significant decrease in osteoclast apoptosis and increase in osteoclast formation that promotes bone resorption $[6,7]$. Estrogen treatment reverses bone loss in estrogen-deficient postmenopausal women and several ovariectomized animal models $[5,7,8]$. The exact mechanisms through which estrogen deficiency and treatment exert these effects are still being determined. A number of signaling pathways has been implicated, including those involving oxidative stress and proinflammatory cytokines, such as TNF- $\alpha$, IL-1, M-CSF, GM-CSF, and IL-6 [5, 9-11]. 
Obesity induced by high-fat diets has been demonstrated to increase bone resorption and/or decrease bone formation resulting in reduced bone mass and strength in various animal models with normal ovary function. Also, bone mineral density and bone strength were not found to be affected by OVX-induced hyperphagia, which indicates increased body weight in obesity is not advantageous to bone health [12-15]. Furthermore, evidence is accumulating that indicates obesity is associated with decreased bone mass and increased fracture risk in humans [16-19]. Recently, Feresin et al. reported that leptin receptor-deficient obese OVX Zucker rats, a genetic rat model for obesity, had lower trabecular thickness than heterozygous lean OVX controls when animals were fed the same normal-fat diet (AIN-93G) [20]. However, the extent to which diet-induced obesity affects bone structure and markers of bone formation and resorption, as well as circulating estrogen levels in an animal model of postmenopause (ovariectomy) is unknown.

The objective of the current study was to determine whether a high-fat diet induced obesity mitigates or exacerbates bone structure deterioration, and alters markers of bone resorption and formation in OVX mice. We hypothesized that a high-fat diet would induce significant increases in body weight gain and serum estradiol concentrations in OVX mice, but would not improve bone structural parameters. To test this hypothesis, bone structure and molecular characteristics of bone metabolism were determined in mice that were OVX or sham operated, then fed a normal or high-fat diet for $11 \mathrm{wks}$. 


\section{Methods and materials}

\subsection{Animals and treatments.}

Thirty-six female C57BL/6 mice age 4-mo were either bilaterally ovariectomized to mimic the postmenopausal osteoporosis or sham-operated (Sham) by Charles River Laboratories (Wilmington, MA). Upon arrival one week after the operation, mice were individually placed in Plexiglas ventilated cages located in an environmentally-controlled pathogen-free facility with a 12-hour light/12-hour dark cycle. The animal protocol for the study was approved by the United States Department of Agriculture Agricultural Research Service Grand Forks Human Nutrition Research Center Animal Care and Use Committee. Animals were maintained and processed in accordance with the NIH Guide for the Care and Use of Laboratory Animals. Mice were fed a Purina Rat Chow \#5012 (Ralston-Purina, St. Louis, MO) while acclimating to our animal facility for 3 days. Then, sham or OVX mice were randomly assigned to two treatment groups ( $\mathrm{n}=9 /$ group) and fed either a normal-fat purified diet (10\% energy as fat, D12450B, Research Diets, New Brunswick, NJ) (Sham-10 or OVX-10) based on AIN-93G [21] or a high-fat diet (45\% energy as fat) with extra fat from lard (Sham-45 or OVX-45) for 11 wks. The composition of the experimental diets is described in Table 1. Mice had free access to diets and tap water throughout the study. Body weights were recorded.

\subsection{Sample preparation.}

At age about 7 mos, mice were euthanized with a ketamine cocktail [1.37:1 mixture of ketamine (Animal Health Co., St. Joseph, MO):xylazine (Phoenix Scientific, St. Joseph, 
MO)]. Blood samples were collected and centrifuged at $1,500 \mathrm{~g}$ for $20 \mathrm{~min}$ at $4^{\circ} \mathrm{C}$ to obtain serum that was stored at $-80^{\circ} \mathrm{C}$ until analyzed.

The right tibia of each mouse was removed, cleaned of adherent tissue, and stored at $20^{\circ} \mathrm{C}$ before being scanned by micro computed tomography $(\mu \mathrm{CT})$ as described below. The right femurs were flash-frozen in liquid nitrogen and stored at $-80^{\circ} \mathrm{C}$ for later total RNA isolation.

\subsection{Bone $\mu \mathrm{CT}$ evaluation.}

Either tibia or femur can be chosen for bone structure because structural parameters in proximal tibia and distal femur are highly correlated [12, 22]. The tibia was placed in a holder of $10.2 \mathrm{~mm}$ in diameter and scanned using a Scanco $\mu \mathrm{CT}$ scanner 40 (Scanco Medical AG, Bassersdorf, Switzerland) at $12 \mu \mathrm{m}$ isotropic voxel size with X-ray source power of $55 \mathrm{kV}$ and $145 \mu \mathrm{A}$ and integration time of 300 milliseconds. The grey-scale images were processed by using a low-pass Gaussian filter $(\operatorname{sigma}=0.8$, support $=1)$ to remove noise, and a fixed threshold of 275 was used to extract the mineralized bone from soft tissue and marrow phase. The reconstruction and 3D quantitative analyses were performed by using software provided by Scanco as previously described [12]. For tibial trabecular bone, 100 slices starting from about $0.1 \mathrm{~mm}$ distal to growth plate were chosen for analyses. The recommended guidelines for $\mu \mathrm{CT}$ scanning and bone histomorphometry nomenclature were followed. For tibial trabecular bone, bone volume $\left(\mathrm{BV}, \mathrm{mm}^{3}\right)$, total volume $\left(\mathrm{TV}, \mathrm{mm}^{3}\right.$ ), BV/TV (ratio of the segmented bone volume to the total volume of the region evaluated, \%), trabecular number (the average number of trabeculae per unit 
length, Tb.N, 1/mm), trabecular thickness (mean thickness of trabeculae, Tb.Th, mm), trabecular separation (mean distance between trabeculae, $\mathrm{Tb} . \mathrm{Sp}, \mathrm{mm}$ ), connectivity density (a degree of connectivity of trabeculae normalized by TV, Conn.D, $1 / \mathrm{mm}^{3}$ ), and structure model index (an indicator of the plate- and rod-like geometry of trabecular structure, SMI) were determined.

\subsection{Measurements of bone biochemical markers}

Serum concentrations of bone biochemical markers were determined by using commercial anti-mice enzyme-linked immunosorbent assay kits according to the manufacturers' instructions: estradiol (Calbiotech, Inc, Spring Valley, CA), tartrateresistant acid phosphatase (TRAP5b, Immunodiagnostic System, Fountain Hill, AZ), osteocalcin (Biomedical Technologies Inc, Stoughton, MA).

\subsection{Measurement of bone mRNA.}

Total RNA was obtained from frozen femurs pulverized with a liquid nitrogen-cooled stainless steel mortar and pestle by using Trizol (Carlsbad, CA) reagent according to the manufacturer's instructions. Denatured total RNA from cells $(2 \mu \mathrm{g})$ was reverse transcribed and amplified and quantified by using a Sequence Detection System (SDS 7300) as previously described [12]. Relative mRNA levels were normalized to levels of GAPDH mRNA in the same sample. The sense and antisense primer sequences were as follows: for osteocalcin 5'-ATC TAT GGC ACC ACC GTT TAG -3', and 5'-CAT ACT TTC GAG GCA GAG AGA G -3'; for integrin B3 5'-TTC AAT GCC ACC TGC CTC AAC AAC-3', and 5'-ACG CAC CTT GGC CTC GAT ACT AAA-3'; for receptor 
activator nuclear factor-KB (RANKL) 5'-CCT GAG GCC CAG CCA TTT -3', and 5'CTT GGC CCA GCC TCG AT -3'; for calcitonin receptor (CTR) 5'- TCC AAG GAG GTC CAG AGT GAA -3', and 5'- TGG GCT CAC TAG GGA GCA GGA -3'; for cathepsin K 5'- GGA AGA AGA CTC ACC AGA AGC -3', and 5'- GTC ATA TAG CCG CCT CCA CAG -3'; for GAPDH 5'- TGC ACC ACC AAC TGC TTA G-3', and 5'- GGA TGC AGG GAT GAT GTT C-3'. All oligonucleotide primers for PCR amplification were designed using PrimerQuest software and synthesized and then purified by HPLC by Integrated DNA Technologies (IDT, Coralville, IA).

\subsection{Statistical Analyses.}

Data are expressed as group means $\pm \mathrm{SD}$ and were analyzed using two-way ANOVA (JMP, version 9.0.0, SAS Institute, Inc.). Repeated two-way ANOVA was used for body weight analysis. Tukey contrasts were performed to compare group means when the Fat $\mathrm{x}$ OVX interaction was significant. One animal in the OVX-45 died at 7-wk of age and was excluded from data analysis. A power analysis indicated that to detect a significant difference in the primary outcome variable of tibia BV/TV among the treatments with a 0.90 power and alpha $=0.05$ [12] would require 9 mice/group. In all of the analyses, $P<$ 0.05 was considered to be statistically significant. 


\section{Results}

There were no differences in initial body weights between Sham and OVX or between normal-fat and high-fat groups (Figure 1). All animals gained weight regardless of treatments, without obvious adverse events. Both OVX and the high-fat diet significantly increased body weight $(\mathrm{P}<0.01$, respectively). At $\mathrm{d} 7$ after the initiation of the treatments (approximately 2.5 wks after OVX), OVX mice had higher body weight than Sham mice $(\mathrm{P}<0.01)$. Starting from d14, mice fed the high-fat diet (Sham-45 and OVX-45) had significantly higher body weight than mice fed the normal-fat diet (Sham-10 and OVX$10, \mathrm{P}<0.01)$. At the end of the study, mice in the OVX and high-fat diet groups had higher body weights than those in the sham-operated and normal-fat diet groups, respectively $(\mathrm{P}<0.01)$. OVX mice fed the high-fat diet were visually obese. Final body weight for OVX mice fed high-fat diet (OVX-45) was greater than any other groups $(\mathrm{P}<$ $0.05)$.

OVX mice and those fed high-fat diets had higher $(\mathrm{P}<0.01)$ serum concentrations of the bone resorption marker TRAP (Figure 2A) than Sham mice and those fed normal-fat diets, respectively. Sham-45, OVX-10, and OVX-45 mice had elevated serum TRAP (P < 0.05) when compared to Sham-10 mice. Ovariectomy or the high-fat diet did not affect serum concentration of the bone formation marker osteocalcin, but an interaction between ovariectomy and the high-fat diet feeding was observed $(\mathrm{P}=0.02)$ (Figure 2B). As expected, OVX decreased serum estradiol concentration (Figure 2C) relative to sham mice $(\mathrm{P}<0.01)$. Compared with normal-fat fed mice, high-fat fed mice had higher serum estradiol concentrations $(P<0.01)$. The serum estradiol concentration of OVX-45 mice 
was similar to that of Sham-10 mice. Sham-45 mice had higher serum estradiol concentrations than all other treatment groups $(\mathrm{P}<0.05)$.

The ovariectomized mouse is a well-accepted model for the study of postmenopausal osteoporosis in response to dietary or drug treatment [23, 24]. As expected, OVX adversely affected three-dimensional bone microstructure (Table 2 and Figure 3). Compared with Sham mice, OVX mice had 36\% less femoral trabecular BV/TV with lower Conn.D, Tb.N, and Tb.Th and greater Tb.Sp, and SMI $(P<0.05)$, indicating rodlike bone microstructure. Consuming the high-fat diet for 11 weeks did not significantly affect bone microstructural parameters but tended to decrease BV/TV (13\% compared to the normal-fat diet, $\mathrm{P}=0.08)$ and Conn. $\mathrm{D}(35 \%$ compared to the normal-fat diet, $\mathrm{P}=$ 0.10). There was an interaction in Tb.Th $(\mathrm{P}<0.05)$ between OVX and the fat diet and OVX-45 mice had the lowest Tb.Th compared to animals in other treatments.

Neither OVX nor high-fat feeding affected the expression of bone resorption genes, RANKL, calcitonin receptor, or integrin $\beta 3$ (Figure 4). However, compared with Sham, OVX increased the expression of cathepsin $\mathrm{K}$, an osteoclast differentiation marker $(\mathrm{P}<$ 0.05). OVX-10 mice had higher cathepsin K expression than Sham-10 mice $(\mathrm{P}<0.05)$. 


\section{Discussion}

Despite being a risk factor for other chronic health disorders, obesity is thought to be beneficial to bone health. The putative beneficial effect is largely based on the premise that increased body weight in obesity would provide greater mechanical loading on bone and therefore stimulate bone formation [2]. In addition, increased estrogen production in obesity would inhibit bone turnover and decrease bone resorption because adipocytes can synthesize estrogen from circulating androgens [3, 25], particularly in decreased estrogen conditions such as in postmenopausal women [26].

Body weight has been positively associated with bone mineral density [27-29]. The mechanical loading apparently stimulates bone formation by decreasing apoptosis and increasing proliferation and differentiation of osteoblasts and osteocytes through the Wnt/ $\beta$-catenin signaling pathway [30]. However, increased body weight in the form of excessive fat accumulation also has been found to be detrimental to bone health [16-19]. The extent to which or whether adipocyte-derived estrogen exerts the same anabolic effect on bone as that from ovary, particularly in low estrogen states, has not been investigated.

The finding that ovariectomy increased body weight starting at about 2.5 wks after OVX, is consistent with those reported for humans and animals [31-33]. Ample evidence suggests that fat mass, not measured in the study, is likely a primary component of the weight gain after ovariectomy. Previously, Chen and Heiman [32] reported that that ovariectomy increased body mass as well as fat mass 24 days after the surgery. Ley et al. 
[31] reported that nonobese healthy postmenopausal women had a $20 \%$ greater fat mass than premenopausal women. Our finding that OVX mice fed a high-fat diet gained more weight than sham mice on the same diet indicates that ovariectomized mice have an increased obesogenic response to a high-fat diet, a finding similar to others [34, 35]. Menopause and OVX result in estrogen reduction, which is generally accompanied by weight gain, primarily as fat mass, in humans and animals [31-34]. The potential role of estrogen in obesity has been demonstrated recently by Riant et al. [36] who found that estrogen treatment protected OVX mice against high-fat diet-induced weight gain and insulin resistance and glucose intolerance. In addition, Heine et al. [37] found that male or female mice lacking estrogen receptor- $\alpha$ had increased adipose tissue.

In the present study, a high-fat diet and OVX increased body weight by 27.4 and $27.2 \%$, respectively, relative to the normal fat diet and sham at the end of the study. And yet, measured bone structural parameters were not improved, indicating that the increased mechanical loading caused by increased body weight in OVX or high-fat diet fed mice did not protect against unfavorable bone changes induced by estrogen reduction or excessive adiposity.

The effects of obesity on bone may depend on the degree of adiposity, duration of the high-fat diet, and other physiological factors [16-19]. The finding that OVX-45 mice had the lowest $\mathrm{Tb}$.Th possibly indicates increased bone resorption in OVX mice fed the highfat diet. Unlike other studies in which mice at 6 wks of age were used [12-14, 38], there were no significant negative effects of obesity on bone structural parameters in the 
present study. Mice started on the high-fat diet at more than 4 months of age, at which peak bone mass is reached and animals are mature [39]. It is likely that adult animals need more time to respond to the high-fat diet than young growing animals. We recognize that obesity in humans is a complex phenomenon that can broadly affect metabolic status and that the relationship between obesity and bone health in humans has been only observational. The high-fat diet induced obesity rodent model may not be appropriate for studying the effects of human obesity on bone because this rodent model is of short duration and the subjects are quadrupedal. However, the rodent model allows control of the degree of adiposity and enables the identification of mechanisms underlying the impact of adiposity on bone health. It also allows for the evaluation of interventions that may mitigate those effects.

This study also found that OVX mice fed a high-fat diet for 11 wks to induce obesity had increased serum estradiol concentrations compared to those of non-obese sham mice fed the normal-fat diet, and yet had lower BV/TV, Conn.D, Tb.N, Tb.Th and higher SMI and Tb.Sp. Similarly, Feresin et al. [20] found that obese OVX Zucker rats, despite having higher body weight, had lower trabecular thickness than lean OVX controls. The Zucker rats, a genetic rat model prone to be obese, were fed the AIN-93G diet not a high-fat diet. However, in that study circulating estrogen concentrations were not measured or reported. The rise in serum estradiol in the present study would be considered physiologically significant because Modder et al. [7] reported that treating OVX mice with $5 \mu \mathrm{g} / \mathrm{kg} /$ day estradiol E2 restored serum E2 concentrations to that of Sham animals and prevented loss of cancellous bone at the lumbar spine and tibial metaphysis. Estrogen 
is primarily produced by the ovary as a circulating hormone to act on distant tissues. However, estrogen can also be synthesized by a number of extragonadal tissues, especially by the adipose tissue when the ovary stops producing estrogen [3].

Studies on the relationship between obesity and circulating estrogen have been mixed in premenopausal women [40-42]. These reports suggest that the amount of estrogen produced by adipose tissue is insignificant compared to that from ovary in premenopausal women. Because adipocytes can synthesize estrogen from androstendion or testosterone, adipose tissue has been considered an important source of estrogen in postmenopausal women that provides protection from further bone loss [3, 25]. In postmenopausal women, the relationship between obesity and bone is confounded by the apparent lack of studies comparing diet- and estrogen reduction-induced obesity and the effect of dietinduced obesity alone on circulating estrogen concentration. Results from this study indicate that increased biosynthesis of estrogen in obesity or any mechanical stimulation caused by increased body weight cannot fully compensate the negative impact of OVX on bone structure characteristics. It is possible that estrogen synthesized by adipose tissue does not have the same anti-resorptive effect on bone as estrogen secreted by ovaries, or an estrogen signaling pathway might be impaired by the high-fat diet. Studies suggested that estrogen produced by fat cells is a paracrine or even intracrine factor rather than an endocrine factor, and thus circulating estrogen levels do not reflect direct estrogen action in postmenopausal women [3, 25]. The rise in circulating estradiol in OVX mice fed the high-fat diet may affect other non-skeletal tissues and remain to be investigated. 
The limitations of this study were that the estrogen/estrogen receptor signaling pathway was not evaluated and the duration of the high-fat diet feeding was relative short (11 wks).

In summary, these results support the hypothesis that increased body weight and elevated serum estradiol concentrations resulting from a high-fat diet feeding do not improve bone structure parameters in OVX mice.

\section{Acknowledgments}

We thank Forrest Nielson for reviewing and revising the manuscript and Steven Dufault and James Lindlauf for preparing experimental diets, conducting animal feeding experiment, laboratory biochemical and micro CT analysis. This work was supported by the USDA Agricultural Research Service program "Bone Metabolism in Obesity," Current Research Information System no. 5450-51000-046-00D.

Conflicts of interest: none. 
Table 1. Composition of experimental diets ${ }^{1}$

\begin{tabular}{|c|c|c|}
\hline Ingredient & Control & High Fat Diet \\
\hline & & \\
\hline Casein, 80 Mesh & 200 & 200 \\
\hline L-Cystine & 3 & 3 \\
\hline Corn starch & 315 & 72.8 \\
\hline Maltodextrin 10 & 35 & 100 \\
\hline Sucrose & 350 & 172.8 \\
\hline Cellulose, BW200 & 50 & 50 \\
\hline Soybean oil & 25 & 25 \\
\hline Lard & 20 & 177.5 \\
\hline Mineral $\operatorname{mix}^{2}$ & 10 & 10 \\
\hline Dicalcium phosphate & 13 & 13 \\
\hline Calcium carbonate & 5.5 & 5.5 \\
\hline Potasium citrate, $1 \mathrm{H} 2 \mathrm{O}$ & 16.5 & 16.5 \\
\hline Vitamin $\operatorname{mix}^{3}$ & 10 & 10 \\
\hline Choline bitartrate & 2 & 2 \\
\hline Total weight, g & 1055 & 858 \\
\hline Energy, $\mathrm{kcal} / \mathrm{g}$ diet & 3.85 & 4.73 \\
\hline \multicolumn{3}{|l|}{$\%$ Energy } \\
\hline Carbohydrate & 70 & 35 \\
\hline Protein & 20 & 20 \\
\hline SFA (\% energy) & 1.5 & 16.6 \\
\hline MUFA (\% energy) & 2.3 & 18.8 \\
\hline PUFA (\% energy) & 6.2 & 9.8 \\
\hline
\end{tabular}

${ }^{1}$ Prepared by Research Diet, Inc., New Brunswick, NJ.

${ }^{2}$ The mineral mix composition was as follows (amount in $10 \mathrm{~g}$ ): $0.5 \mathrm{~g} \mathrm{Mg}, 0.3 \mathrm{~g} \mathrm{~S}, 1.0 \mathrm{~g}$ $\mathrm{Na}, 1.6 \mathrm{~g} \mathrm{Cl}, 6.0 \mathrm{mg} \mathrm{Cu}, 0.2 \mathrm{mg} \mathrm{I}, 45.0 \mathrm{mg} \mathrm{Fe}, 59 \mathrm{mg} \mathrm{Mn}, 0.2 \mathrm{mg} \mathrm{Se}$ and $29 \mathrm{mg} \mathrm{Zn}$.

${ }^{3}$ The vitamin mix composition was as follows (amount in $10 \mathrm{~g}$ ): $4000 \mathrm{IU}$ vitamin A palmitate, 1,000 IU cholecalciferol, $50 \mathrm{IU}$ vitamin E acetate, $0.5 \mathrm{mg}$ menadione sodium bisulfite, $0.2 \mathrm{mg}$ biotin, $10 \mu \mathrm{g}$ cyanocobalamin, $2 \mathrm{mg}$ folic acid, $30 \mathrm{mg}$ nicotinic acid, 16 $\mathrm{mg}$ calcium pantothenate, $7 \mathrm{mg}$ pyridoxine- $\mathrm{HCl}, 6 \mathrm{mg}$ riboflavin, $6 \mathrm{mg}$ thiamin $\mathrm{HCl}$. 


\section{TABLE 2}

Trabecular bone structural properties of proximal tibia from Sham or OVX mice fed either a purified normal-fat (10\% energy as fat) or a high-fat (45\% energy as fat) diet for $11 \mathrm{wks}^{1}$

\begin{tabular}{|c|c|c|c|c|c|c|c|}
\hline \multirow[b]{2}{*}{ Indices } & \multirow[b]{2}{*}{ Sham-10 } & \multirow[b]{2}{*}{ OVX-10 } & \multirow[b]{2}{*}{ Sham-45 } & \multirow[b]{2}{*}{ OVX-45 } & \multicolumn{3}{|c|}{ ANOVA (P value) } \\
\hline & & & & & Fat & OVX & Fat $x$ OVX \\
\hline $\mathrm{BV}, \mathrm{mm}^{3}$ & $0.17 \pm 0.03$ & $0.11 \pm 0.01$ & $0.15 \pm 0.04$ & $0.11 \pm 0.02$ & 0.127 & $<0.001$ & 0.366 \\
\hline $\mathrm{TV}, m m^{3}$ & $2.50 \pm 0.19$ & $2.69 \pm 0.17$ & $2.54 \pm 0.13$ & $2.64 \pm 0.21$ & 0.894 & 0.024 & 0.417 \\
\hline $\mathrm{BV} / \mathrm{TV}, \%$ & $6.8 \pm 1.3$ & $4.1 \pm 0.5$ & $5.8 \pm 1.2$ & $3.9 \pm 0.8$ & 0.083 & $<0.001$ & 0.244 \\
\hline Tb.N, $m m^{-1}$ & $2.07 \pm 0.33$ & $1.68 \pm 0.10$ & $1.98 \pm 0.37$ & $1.64 \pm 0.32$ & 0.522 & 0.001 & 0.819 \\
\hline Tb.Th, $m m$ & $0.07 \pm 0.01^{\mathrm{a}}$ & $0.06 \pm 0.01^{\mathrm{ab}}$ & $0.06 \pm 0.01^{\mathrm{ab}}$ & $0.06 \pm 0.01^{b}$ & 0.339 & 0.036 & 0.021 \\
\hline Tb.Sp, $m m$ & $0.52 \pm 0.06$ & $0.59 \pm 0.04$ & $0.52 \pm 0.10$ & $0.63 \pm 0.12$ & 0.461 & 0.003 & 0.514 \\
\hline Conn.Dn, $\mathrm{mm}^{-3}$ & $13.2 \pm 6.1$ & $6.1 \pm 3.0$ & $9.0 \pm 4.5$ & $5.3 \pm 3.6$ & 0.097 & $<0.001$ & 0.259 \\
\hline SMI & $2.12 \pm 0.17$ & $1.68 \pm 0.10$ & $1.98 \pm 0.37$ & $1.64 \pm 0.32$ & 0.262 & $<0.001$ & 0.894 \\
\hline
\end{tabular}

${ }^{1}$ Proximal tibia microstructure was evaluated with Scanco micro computed tomography scanner 40 at $12 \mu \mathrm{m}$ isotropic voxel size with $\mathrm{X}$-ray source power of $55 \mathrm{kV}$ and $145 \mu \mathrm{A}$ and integration time of 300 milliseconds. One hundred slices starting from $0.1 \mathrm{~mm}$ below 
the growth plate were analyzed with a fixed threshold of 275 to extract the mineralized bone from soft tissue and marrow phase. Values are means \pm SD ( $n=9$ for each group except $n=8$ for OVX-45). Data were analyzed by two-way ANOVA. Tukey contrasts were performed to compare differences in Tb.Th among the groups. Labeled means without a common superscript letter differ, $P<$ 0.05. BV, bone volume; Conn.D, connectivity density; OVX-10, ovariectomized mice fed 10\% energy as fat diet; OVX-45, ovariectomized mice fed $45 \%$ energy as fat diet; Sham-10, sham-operated mice fed 10\% energy as fat diet; Sham-45, sham-operated mice fed 45\% energy as fat diet; SMI, Structure Model Index; Tb.N, trabecular number; Tb.Sp, trabecular separation; Tb.Th, trabecular thickness; TV, total volume. 


\section{Literature Cited}

[1] Villareal DT, Apovian CM, Kushner RF, Klein S. Obesity in older adults: technical review and position statement of the American Society for Nutrition and NAASO, The Obesity Society. The American journal of clinical nutrition. 2005;82:923-34.

[2] Reid IR. Relationships between fat and bone. Osteoporos Int. 2008;19:595-606.

[3] Simpson ER. Sources of estrogen and their importance. J Steroid Biochem Mol Biol. 2003;86:225-30.

[4] Looker AC, Borrud LG, Dawson-Hughes B, Shepherd JA, Wright NC. Osteoporosis or low bone mass at the femur neck or lumbar spine in older adults: United States, 20052008. NCHS data brief. 2012:1-8.

[5] Riggs BL, Khosla S, Melton LJ, 3rd. Sex steroids and the construction and conservation of the adult skeleton. Endocr Rev. 2002;23:279-302.

[6] Pacifici R, Brown C, Puscheck E, Friedrich E, Slatopolsky E, Maggio D, et al. Effect of surgical menopause and estrogen replacement on cytokine release from human blood mononuclear cells. Proceedings of the National Academy of Sciences of the United States of America. 1991;88:5134-8.

[7] Modder UI, Riggs BL, Spelsberg TC, Fraser DG, Atkinson EJ, Arnold R, et al. Doseresponse of estrogen on bone versus the uterus in ovariectomized mice. Eur J Endocrinol. 2004;151:503-10.

[8] Sims NA, Morris HA, Moore RJ, Durbridge TC. Estradiol treatment transiently increases trabecular bone volume in ovariectomized rats. Bone. 1996;19:455-61.

[9] Pfeilschifter J, Koditz R, Pfohl M, Schatz H. Changes in proinflammatory cytokine activity after menopause. Endocr Rev. 2002;23:90-119.

[10] Kimble RB, Matayoshi AB, Vannice JL, Kung VT, Williams C, Pacifici R.

Simultaneous block of interleukin-1 and tumor necrosis factor is required to completely prevent bone loss in the early postovariectomy period. Endocrinology. 1995;136:305461.

[11] Lorenzo JA, Naprta A, Rao Y, Alander C, Glaccum M, Widmer M, et al. Mice lacking the type I interleukin-1 receptor do not lose bone mass after ovariectomy. Endocrinology. 1998;139:3022-5.

[12] Cao JJ, Gregoire BR, Gao H. High-fat diet decreases cancellous bone mass but has no effect on cortical bone mass in the tibia in mice. Bone. 2009;44:1097-104.

[13] Kyung TW, Lee JE, Phan TV, Yu R, Choi HS. Osteoclastogenesis by bone marrowderived macrophages is enhanced in obese mice. J Nutr. 2009;139:502-6.

[14] Chen JR, Zhang J, Lazarenko OP, Cao JJ, Blackburn ML, Badger TM, et al. Soy protein isolates prevent loss of bone quantity associated with obesity in rats through regulation of insulin signaling in osteoblasts. FASEB J. 2013;27:3514-23.

[15] Jiang JM, Sacco SM, Ward WE. Ovariectomy-induced hyperphagia does not modulate bone mineral density or bone strength in rats. J Nutr. 2008;138:2106-10. [16] Zhao LJ, Liu YJ, Liu PY, Hamilton J, Recker RR, Deng HW. Relationship of obesity with osteoporosis. J Clin Endocrinol Metab. 2007;92:1640-6.

[17] Johansson H, Kanis JA, Oden A, McCloskey E, Chapurlat RD, Christiansen C, et al. A meta-analysis of the association of fracture risk and body mass index in women. $\mathrm{J}$

Bone Miner Res. 2014;29:223-33. 
[18] Rosen CJ, Bouxsein ML. Mechanisms of disease: is osteoporosis the obesity of bone? Nat Clin Pract Rheumatol. 2006;2:35-43.

[19] Shapses SA, Sukumar D. Bone metabolism in obesity and weight loss. Annual review of nutrition. 2012;32:287-309.

[20] Feresin RG, Johnson SA, Elam ML, Jo E, Arjmandi BH, Hakkak R. Effects of obesity on bone mass and quality in ovariectomized female Zucker rats. Journal of obesity. 2014;2014:690123.

[21] Reeves PG, Nielsen FH, Fahey GC, Jr. AIN-93 purified diets for laboratory rodents: final report of the American Institute of Nutrition ad hoc writing committee on the reformulation of the AIN-76A rodent diet. J Nutr. 1993;123:1939-51.

[22] Cao JJ, Sun L, Gao H. Diet-induced obesity alters bone remodeling leading to decreased femoral trabecular bone mass in mice. Ann N Y Acad Sci. 2010;1192:292-7. [23] Kalu DN. The ovariectomized rat model of postmenopausal bone loss. Bone and mineral. 1991;15:175-91.

[24] Riggs BL. The mechanisms of estrogen regulation of bone resorption. J Clin Invest. 2000;106:1203-4.

[25] Nelson LR, Bulun SE. Estrogen production and action. Journal of the American Academy of Dermatology. 2001;45:S116-24.

[26] Reid IR. Relationships among body mass, its components, and bone. Bone.

2002;31:547-55.

[27] Felson DT, Zhang Y, Hannan MT, Anderson JJ. Effects of weight and body mass index on bone mineral density in men and women: the Framingham study. J Bone Miner Res. 1993;8:567-73.

[28] Ravn P, Cizza G, Bjarnason NH, Thompson D, Daley M, Wasnich RD, et al. Low body mass index is an important risk factor for low bone mass and increased bone loss in early postmenopausal women. Early Postmenopausal Intervention Cohort (EPIC) study group. J Bone Miner Res. 1999;14:1622-7.

[29] Robling AG, Castillo AB, Turner CH. Biomechanical and molecular regulation of bone remodeling. Annual review of biomedical engineering. 2006;8:455-98. [30] Ehrlich PJ, Lanyon LE. Mechanical strain and bone cell function: a review. Osteoporos Int. 2002;13:688-700.

[31] Ley CJ, Lees B, Stevenson JC. Sex- and menopause-associated changes in body-fat distribution. Am J Clin Nutr. 1992;55:950-4.

[32] Chen Y, Heiman ML. Increased weight gain after ovariectomy is not a consequence of leptin resistance. Am J Physiol Endocrinol Metab. 2001;280:E315-22.

[33] McElroy JF, Wade GN. Short- and long-term effects of ovariectomy on food intake, body weight, carcass composition, and brown adipose tissue in rats. Physiol Behav. 1987;39:361-5.

[34] Hong J, Stubbins RE, Smith RR, Harvey AE, Nunez NP. Differential susceptibility to obesity between male, female and ovariectomized female mice. Nutrition journal. 2009;8:11.

[35] Nunez NP, Perkins SN, Smith NC, Berrigan D, Berendes DM, Varticovski L, et al. Obesity accelerates mouse mammary tumor growth in the absence of ovarian hormones. Nutrition and cancer. 2008;60:534-41. 
[36] Riant E, Waget A, Cogo H, Arnal JF, Burcelin R, Gourdy P. Estrogens protect against high-fat diet-induced insulin resistance and glucose intolerance in mice.

Endocrinology. 2009;150:2109-17.

[37] Heine PA, Taylor JA, Iwamoto GA, Lubahn DB, Cooke PS. Increased adipose tissue in male and female estrogen receptor-alpha knockout mice. Proc Natl Acad Sci U S A. 2000;97:12729-34.

[38] Cao JJ, Picklo MJ. N-acetylcysteine supplementation decreases osteoclast differentiation and increases bone mass in mice fed a high-fat diet. J Nutr. 2014;144:28996.

[39] Halloran BP, Ferguson VL, Simske SJ, Burghardt A, Venton LL, Majumdar S.

Changes in bone structure and mass with advancing age in the male C57BL/6J mouse. $\mathrm{J}$ Bone Miner Res. 2002;17:1044-50.

[40] Paxton RJ, King DW, Garcia-Prieto C, Connors SK, Hernandez M, Gor BJ, et al. Associations between body size and serum estradiol and sex hormone-binding globulin levels in premenopausal African American women. J Clin Endocrinol Metab. 2013;98:E485-90.

[41] Barnett JB, Woods MN, Rosner B, McCormack C, Longcope C, Houser RF, Jr., et al. Sex hormone levels in premenopausal African-American women with upper and lower body fat phenotypes. Nutrition and cancer. 2001;41:47-56.

[42] Freeman EW, Sammel MD, Lin H, Gracia CR. Obesity and reproductive hormone levels in the transition to menopause. Menopause. 2010;17:718-26. 


\section{Figure Legends}

\section{Figure 1}

Body weight changes in Sham or OVX mice fed either a purified normal-fat (10\% energy as fat) or a high-fat (45\% energy as fat) diet for 11 wks. Values are means \pm SD ( $n=9$ for each group except $n=8$ for OVX-45). Data were analyzed by repeated two-way ANOVA. Tukey contrasts were performed to compare group means when the Fat x OVX interaction was significant. $\mathrm{P}$ values shown below the figure were generated from repeated two-way ANOVA. Labeled means without a common letter differ, $P<0.05$. OVX-10, ovariectomized mice fed $10 \%$ energy as fat diet; OVX-45, ovariectomized mice fed $45 \%$ energy as fat diet; Sham-10, sham-operated mice fed $10 \%$ energy as fat diet; Sham-45, sham-operated mice fed $45 \%$ energy as fat diet.

\section{Figure 2}

Serum estradiol (A), TRAP (B), and osteocalcin (C) concentrations in Sham or OVX mice fed either a purified normal-fat (10\% energy as fat) or a high-fat (45\% energy as fat) diet for 11 wks. Values are means \pm SD ( $n=9$ for each group except $n=8$ for OVX-45). Data were analyzed by two-way ANOVA. OVX-10, ovariectomized mice fed $10 \%$ energy as fat diet; OVX-45, ovariectomized mice fed $45 \%$ energy as fat diet; Sham-10, sham-operated mice fed $10 \%$ energy as fat diet; Sham-45, sham-operated mice fed $45 \%$ energy as fat diet; TRAP, tartrate-resistant acid phosphatase.

\section{Figure 3}


Representative micro computed tomography derived three-dimensional images of proximal tibia in Sham or OVX mice fed either a purified normal-fat (10\% energy as fat) or a high-fat (45\% energy as fat) diet for 11 wks.

\section{Figure 4}

Expression of receptor activator nuclear factor-KB (RANKL), Cathepsin K (CTSK), calcitonin receptor (CTR), and integrin b3 (Itgb3) in whole femur of Sham or OVX mice fed either a purified normal-fat (10\% energy as fat) or a high-fat (45\% energy as fat) diet for 11 wks. Values were normalized to expression GAPDH and expressed relative to data from Sham-10. Values are means $\pm S D$ ( $n=9$ for each group except $n=8$ for OVX-45). Data were analyzed by two-way ANOVA and P values are shown below the figure. OVX-10, ovariectomized mice fed 10\% energy as fat diet; OVX-45, ovariectomized mice fed $45 \%$ energy as fat diet; Sham-10, sham-operated mice fed 10\% energy as fat diet; Sham- 45 , sham-operated mice fed $45 \%$ energy as fat diet. 
Figure 1

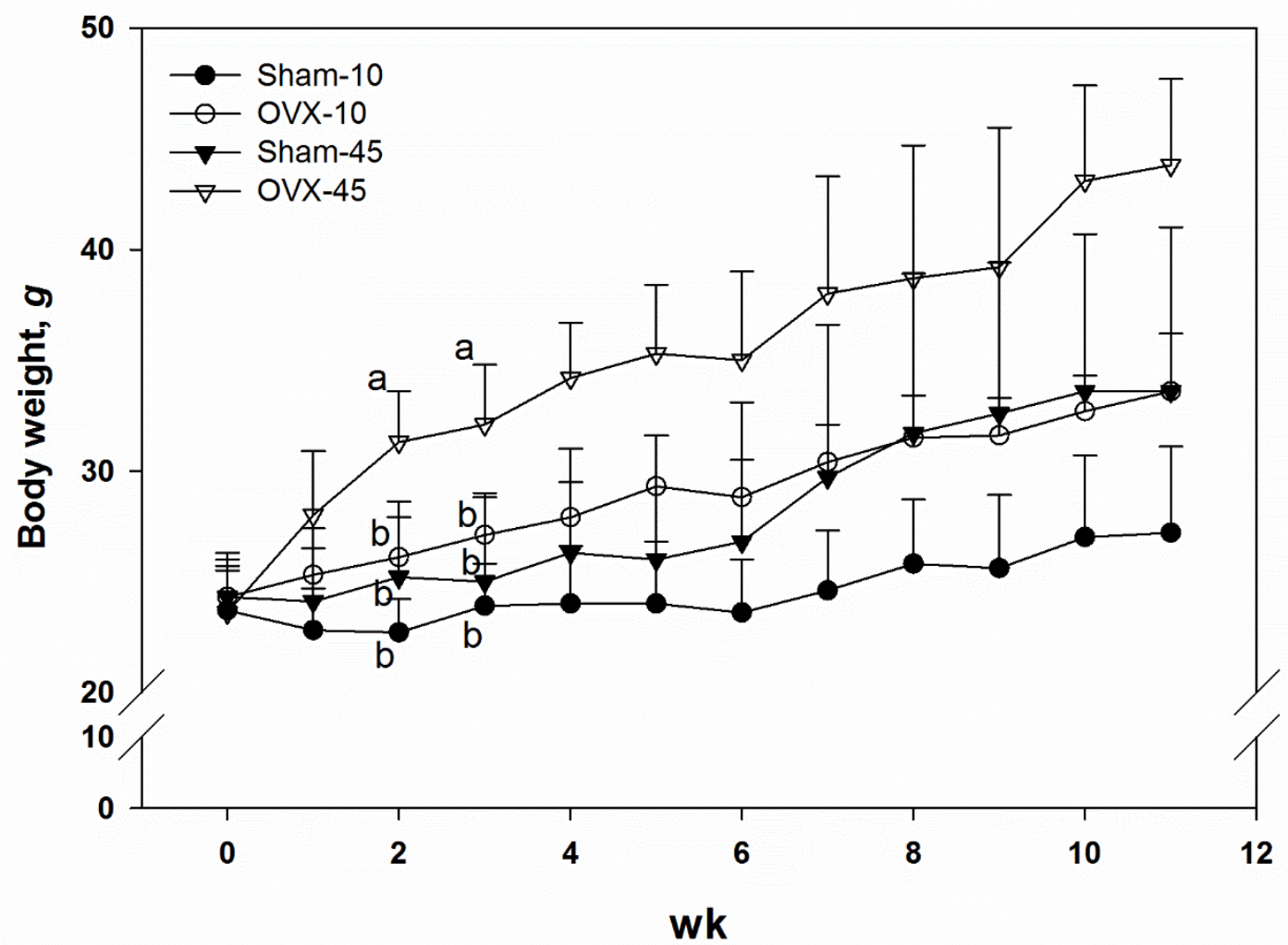

\begin{tabular}{lllllllllllll} 
Week & 0 & 1 & 2 & 3 & 4 & 5 & 6 & 7 & 8 & 9 & 10 & 11 \\
\hline Fat & - & - & $* *$ & $* *$ & $* *$ & $* *$ & $* *$ & $* *$ & $* *$ & $* *$ & $* *$ & $* *$ \\
OVX & - & $* *$ & $* *$ & $* *$ & $* *$ & $* *$ & $* *$ & $* *$ & $* *$ & $* *$ & $* *$ & $* *$ \\
Fat ${ }^{*}$ OVX & - & - & $*$ & $*$ & - & - & - & - & - & - & - & - \\
\hline
\end{tabular}


Figure 2A

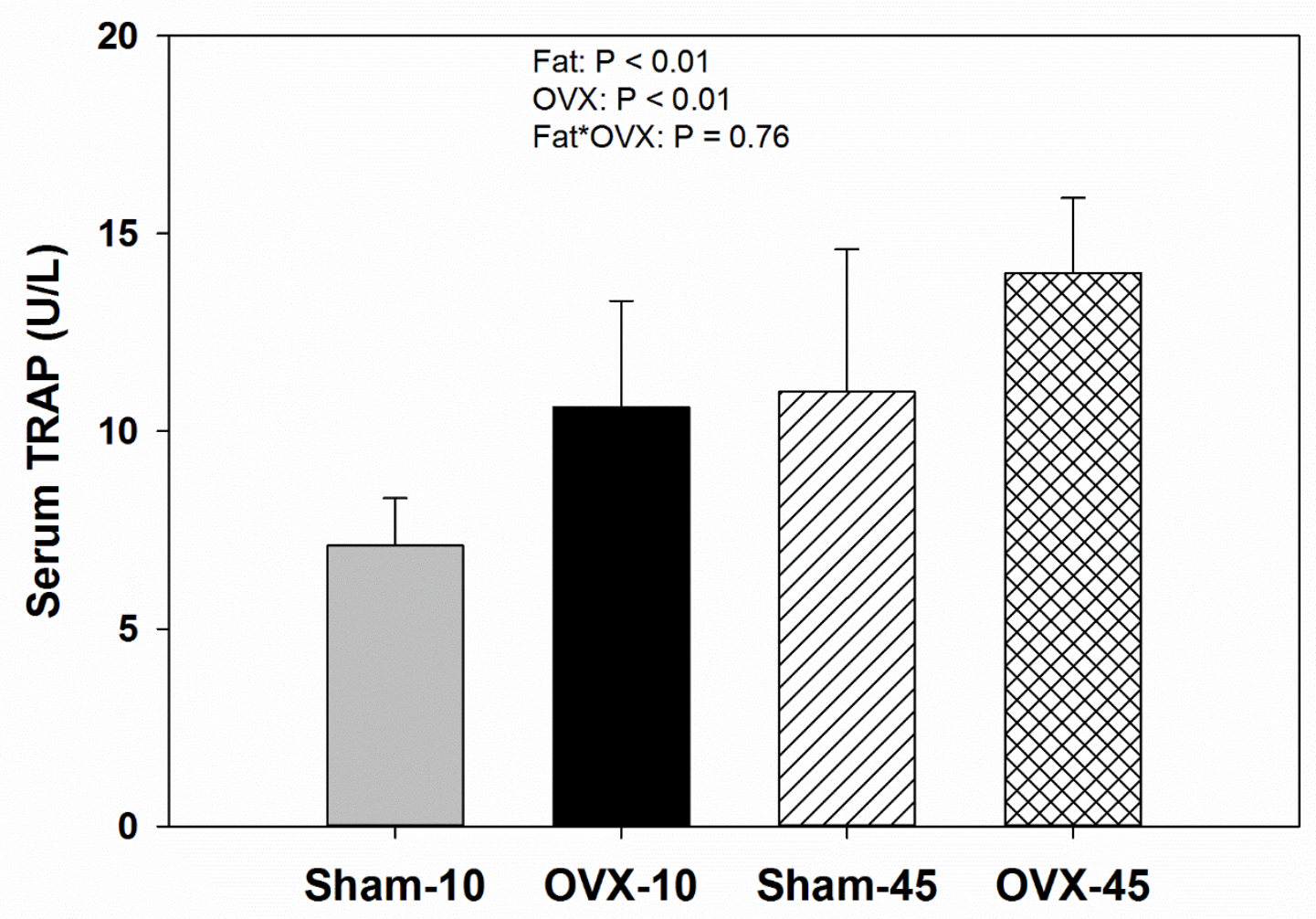


Figure 2B

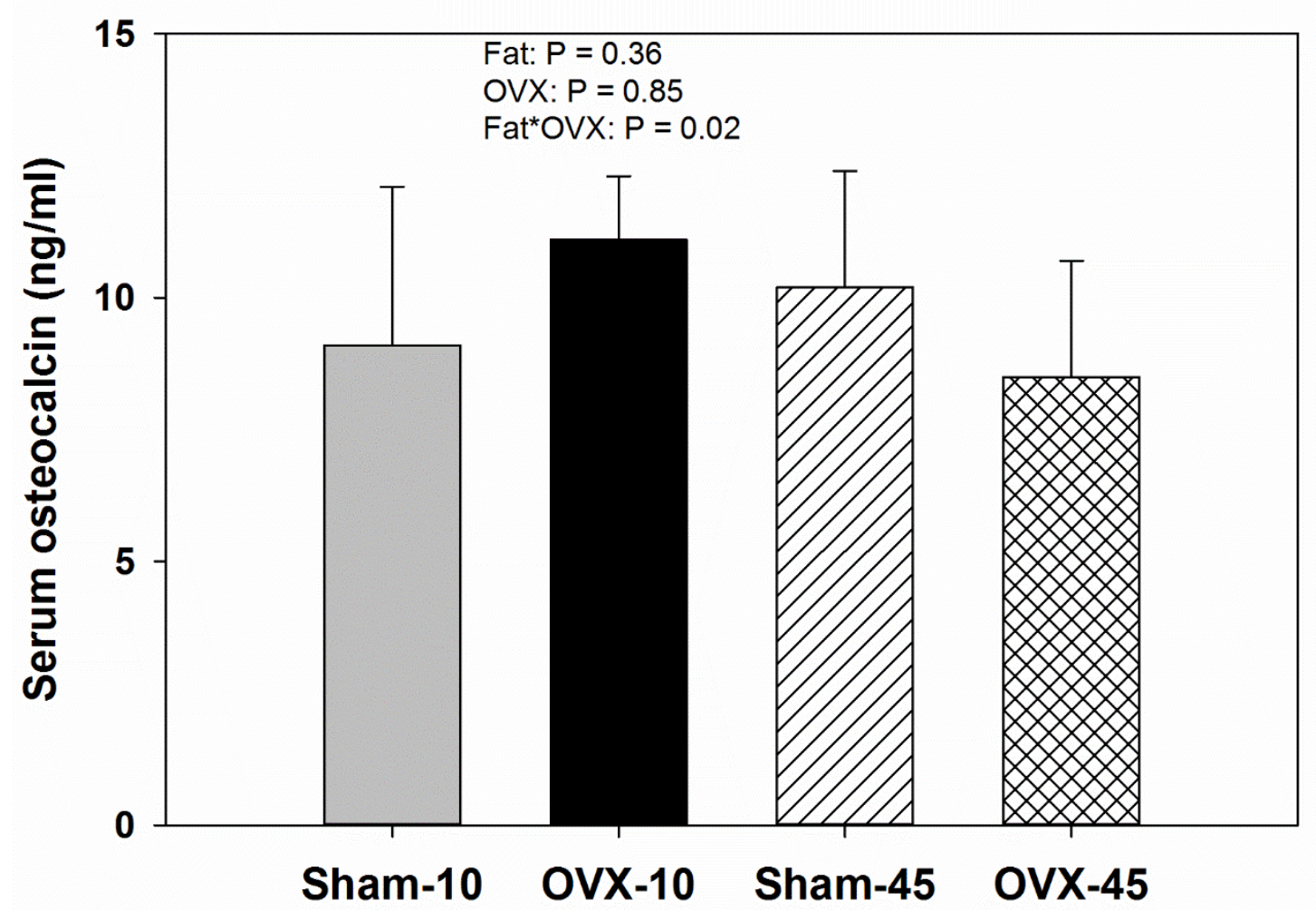


Figure 2C

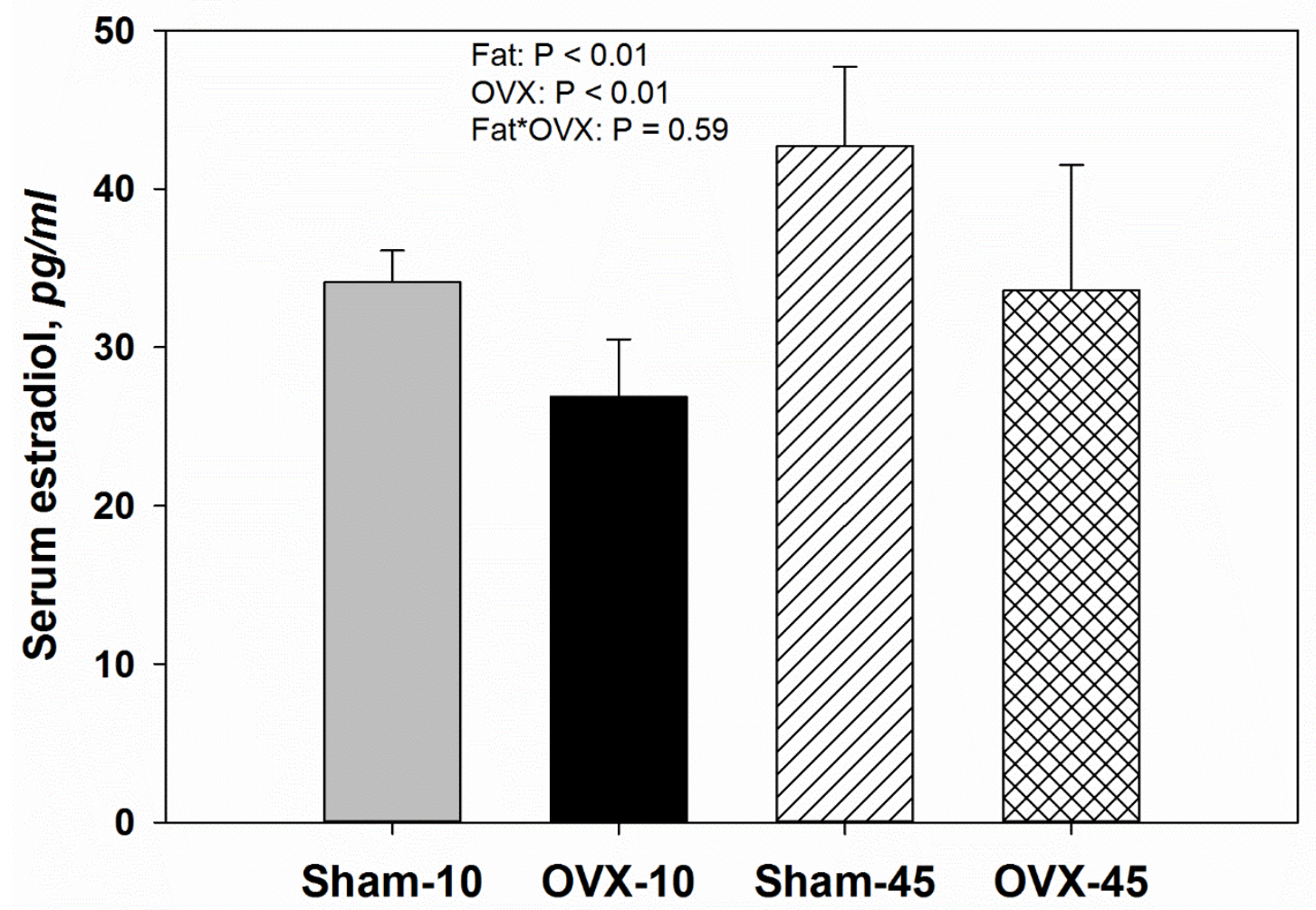


Figure 3

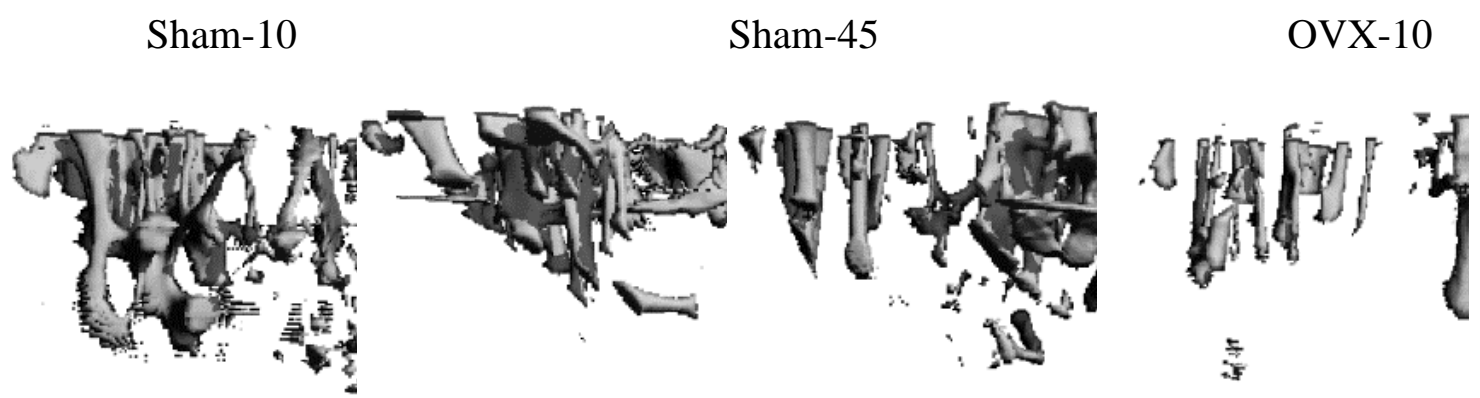


Figure 4

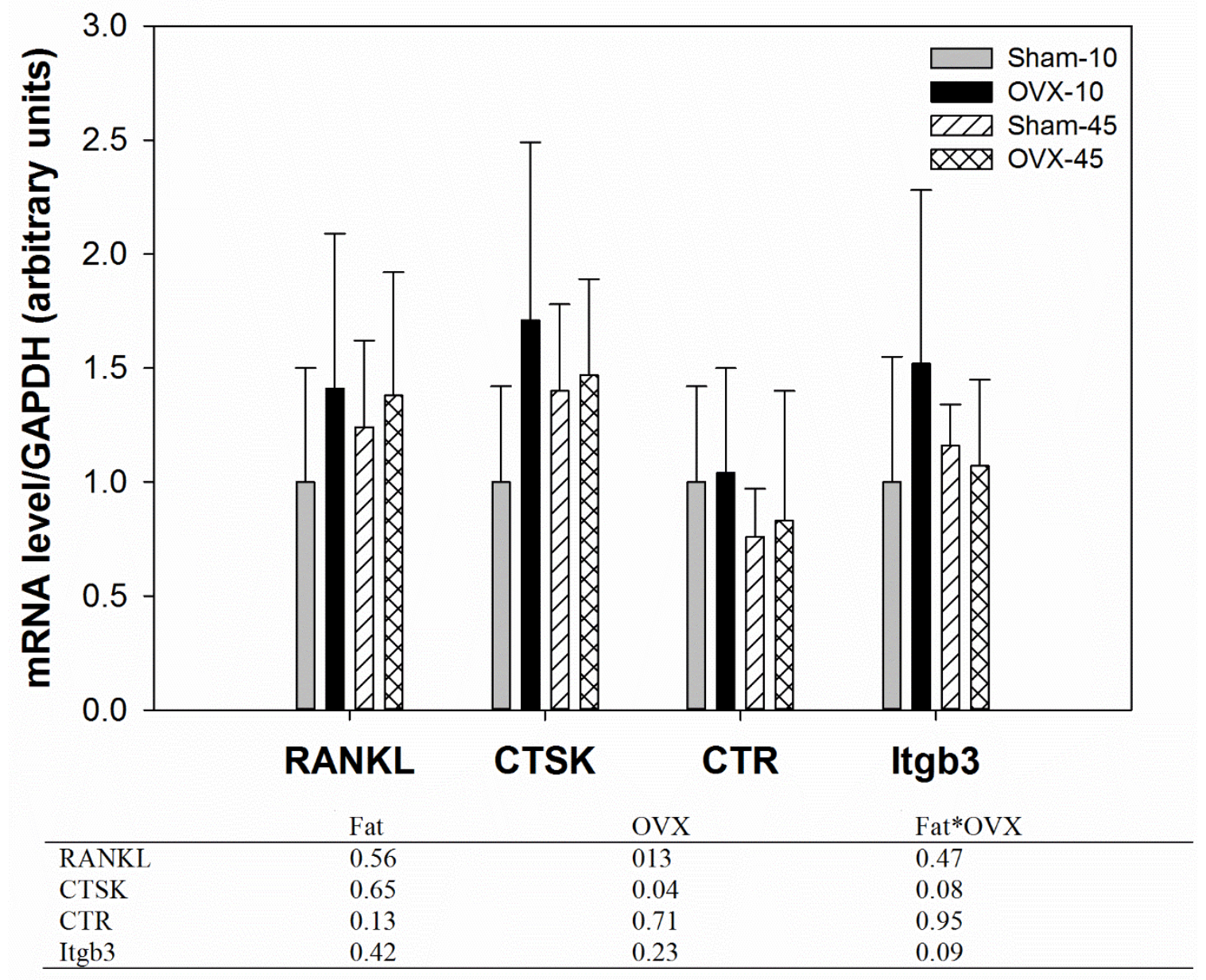

